УДК 618.2:159.942]:005.32

DOI 10.11603/24116-4944.2017.1.7373

\author{
๑̈. Г. Сюсюка, О. В. Комарова, О. В. Пейчева, Е. Г. Аверченко \\ Запорізъкий державний медичний університет \\ Пологовий будинок № 9 м. Запоріжжя

\section{МОТИВАЦІЙНІ АСПЕКТИ ПСИХОЕМОЦІЙНОГО СТАНУ ЖІНОК ПІД ЧАС ВАГІТНОСТІ. АНАЛІЗ ХАРАКТЕРИСТИК ГЕСТАЦІЙНОЇ ДОМІНАНТИ У КОНТЕКСТI ТРИВОЖНОСТI}

\begin{abstract}
Мета дослідження - на підставі оцінки психоемоційного стану вагітних провести аналіз характеристик гестаційної домінанти у контексті тривожності.

Матеріали та методи. Обстежено 336 вагітних у II та III триместрах $((26,29 \pm 0,55)$ тижня). Індивідуально-психологічні особливості вагітних та їх психоемоційний стан досліджували з використанням комплексу психодіагностичних методів, таких, як: особистісний опитувальник Бехтерєвського інституту, шкала Спілбергера - Ханіна, тест відносин вагітної І. В. Добрякова. Варіаційно-статистична обробка результатів здійснювалась з використанням програм аналізу «STATISTICA 6.0».

Результати дослідження та їх обговорення. Результати оцінки особистісної тривожності (ОТ) дозволили встановити, що у 330 (98,21 \%) вагітних їі рівень виходить за межі низьких показників. Такі результати характерні і для ситуативної тривожності (СТ), де середні та високі показники встановлені у 256 вагітних, що склало 76,19\%. Оптимальний варіант психологічного компонента гестаційної домінанти (ПКГД) встановлений лише у 41 (12,20 \%) вагітної, а ейфорійний - у 3 (0,89 \%). У 292 вагітних, що склало 86,91 \%, не встановлено переважання балів на користь конкретного типу ПкГД (тип, який відхиляється від оптимального). Аналіз характеристик гестаційної домінанти в контексті тривожності показав, що показник балів, який характеризує оптимальний тип та оцінений з урахуванням рівня СТ, був статистично достовірно $(p<0,05)$ нижчим у вагітних з високим рівнем CT $((4,10 \pm 0,60)$ бала) порівняно з відповідним показником вагітних, як з середнім $((4,68 \pm 0,22)$ бала), так і низьким ії рівнем $((4,94 \pm 0,36)$ бала).

Висновки. На підставі оцінки психологічного компонента гестаційної домінанти встановлено, що його оптимальний варіант мав місце лише у 12,20 \% вагітних. У більшості вагітних $(86,91 \%)$ не встановлено переважання балів на користь конкретного типу. Аналіз характеристик гестаційної домінанти в контексті тривожності показав, що показник балів, який характеризує оптимальний тип та оцінений з урахуванням рівня СТ, був статистично достовірно $(p<0,05)$ нижчим у вагітних з високим рівнем СТ порівняно з відповідним показником вагітних, як з середнім, так і низьким їі рівнем.
\end{abstract}

Ключові слова: вагітність; психоемоційний стан; психологічний компонент гестаційної домінанти; тривожність.

МОТИВАЦИОННЫЕ АСПЕКТЫ ПСИХОЭМОЦИОНАЛЬНОГО СОСТОЯНИЯ ЖЕНЩИН ВО ВРЕМЯ БЕРЕМЕННОСТИ. АНАЛИЗ ХАРАКТЕРИСТИК ГЕСТАЦИОННОЙ ДОМИНАНТЫ В КОНТЕКСТЕ ТРЕВОЖНОСТИ

Цель исследования - на основании оценки психоэмоционального состояния беременных провести анализ характеристик гестационной доминанты в контексте тревожности.

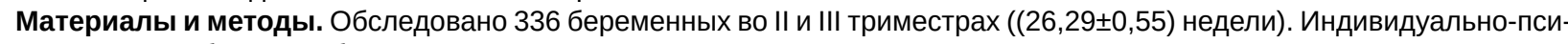
хологические особенности беременных и их психоэмоциональное состояние исследовали с использованием комплекса психодиагностических методов, таких, как: личностный опросник Бехтеревского института, шкала Спилбергера - Ханина, тест отношений беременной И. В. Добрякова. Вариационно-статистическая обработка результатов осуществлялась с использованием программ анализа «STATISTICA 6.0».

Результаты исследования и их обсуждение. Результаты оценки личностной тревожности (ЛТ) позволили установить, что у 330 (98,21 \%) беременных ее уровень выходит за пределы низких показателей. Такие результаты характерны и для ситуативной тревожности (СТ), где средние и высокие показатели установлены у 256 беременных, что составило 76,19\%. Оптимальный вариант психологического компонента гестационной доминанты (ПКГД) установлен лишь у 41 (12,20 \%) беременной, а эйфорический - у 3 (0,89 \%). У 292 беременных, что составило 86,91 \%, не установлено преобладания баллов в пользу конкретного типа ПКГД (отклоняющийся от оптимального). Анализ характеристик гестационной доминанты в контексте тревожности показал, что показатель баллов, характеризующий оптимальный тип и оценен с учетом уровня СТ, был статистически достоверно $(p<0,05)$ ниже у беременных с высоким ее уровнем $((4,10 \pm 0,60)$ балла) по сравнению с соответствующим показателем беременных, как со средним $((4,68 \pm 0,22)$ балла), так и низким ее уровнем $((4,94 \pm 0,36)$ балла).

Выводы. Оценка психологического компонента гестационной доминанты позволила установить, что его оптимальный вариант имел место лишь у 12,20 \% беременных, а у большинства беременных $(86,91$ \%) не установлено преобладания баллов в пользу конкретного типа. Анализ характеристик гестационной доминанты в контексте тревожности показал, что показатель баллов, характеризующий оптимальный тип и оценен с учетом уровня СТ, был статистически достоверно $(p<0,05)$ ниже у беременных с высоким уровнем СТ по сравнению с соответствующим показателем беременных, как со средним, так и с низким ее уровнем.

Ключевые слова: беременность; психоэмоциональное состояние; психологический компонент гестационной доминанты; тревожность.

MOTIVATIONAL ASPECTS OF PSYCHOEMOTIONAL STATE OF WOMEN DURING PREGNANCY. ANALYSIS OF CHARACTERISTICS OF GESTATIONAL DOMINANT WITHIN THE FRAMEWORK OF ANXIETY

The aim of the study - to analyze gestational dominant within the framework of anxiety based on estimation of psychoemotional state of pregnant women. 
Materials and Methods. 336 pregnant women were examined in II and III trimesters (26.29 \pm 0.55 week). Individual and psychological features of pregnant women and their psychoemotional state were studied using the complex of psychodiagnostic methods: Personality Questionnaire of Bekhterev University, Spielberger-Hanin scale, Pregnant Woman Attitude Test of I.V. Dobryakov. Variation and statistical processing of results was performed with STATISTICA 6.0 analysis programs.

Results and Discussion. Results of estimation of trait anxiety (TA) permit to determine that its level of 330 (98.21 \%) pregnant women exceeds the bounds of low indices. Also such results are typical for state anxiety (SA) where medium and high indices are determined in 256 pregnant women that made $76.19 \%$. Optimal variant of psychological component of gestational dominant (PCGD) is determined in $41(12.20 \%)$ pregnant women and euphoric one - in $3(0.89 \%)$ pregnant women. Prevalence of points in favour of certain type of PCGD (type which deviates from the optimal variant) was not determined in 292 pregnant women that made $86.91 \%$. Analysis of characteristics of gestational dominant within framework of anxiety showed that indicator of points (which characterizes optimal type and is estimated with consideration of SA level) was statistically proved $(p<0.05)$ and lower in pregnant women with high SA level ( $4.10 \pm 0.60$ points) comparing to appropriate index of pregnant women with both medium (4.68 \pm 0.22 points) and lower ( $4.94 \pm 0.36$ points) levels.

Conclusions. Estimation of psychological component of gestational dominant permitted to determine the fact that its optimal variant occurred only in $12.20 \%$ of pregnant women. Prevalence of points in favour of certain type was not determined in majority of pregnant women (86.91\%). Analysis of characteristics of gestational dominant within framework of anxiety showed that index of points which characterizes optimal type and is estimated with consideration of SA level was statistically proved $(p<0.05)$ and lower in pregnant women with high SA level comparing to appropriate index of pregnant women with both medium and low level of SA.

Key words: pregnancy; psychoemotional state; psychological component of gestational dominant; anxiety.

ВстУП. Дослідження науковців протягом десятиліть дозволили істотно переосмислити класичне уявлення про системну організацію процесів жіночої репродукції та значною мірою ії̈ доповнити. Гестаційна домінанта не тільки викликає фрізіологічну перебудову в організмі матері, але і впливає на їі емоційний стан. Серед усіх теоретичних та експериментальних досліджень особливе місце належить домінанті, яка пов'язана з репродукцією, що в науковий обіг увійшло терміном «статева домінанта». Принцип її існування полягає у тому, що домінанта припиняє своє існування після реалізації біологічної потреби або після того, як в силу тих чи інших причин припиняється підтримуючий її вплив аферентних нервових або гуморальних сигналів. Домінанта зникає в тих випадках, коли вона витісняється новою домінантою [1] Психологічний компонент гестаційної домінанти (ПКГД) готує фрізіологію майбутньої матері до зачаття. Він виникає ще до запліднення і характеризується так званими домінуючими ідеями зачаття та вагітності, відображаючи гостре бажання жінки мати дитину [2]. На підставі вивчення анамнестичних даних, клініко-психологічних спостережень за вагітними і бесід з ними І. В. Добряковим було виділено п'ять типів ПКГД: оптимальний, гіпогестогнозичний, ейфорійний, тривожний та депресивний [3, 4]. Однак саме оптимальний тип ПКГД сприяє виношуванню здорового плода, згодом народженню здорової дитини. Крім того, оптимальний тип налаштовує жінку на прийняття дитини незалежно від стану її здоров'я, що важливо для формування діади «мати - дитя» та позитивного психологічного клімату в сім'ї [5]. Типи ПКГД можуть змінюватися протягом вагітності залежно від терміну гестації, соматичного стану жінки, ситуації в сім'ї, відносин, що складаються з лікарем, тощо [6]. Втім, слід зазначити, що тест відносин вагітної є допоміжною методикою, яка дозволяє отримати приблизне уявлення про варіант ПКГД, її використання не дозволяє виявити конкретні проблеми сім'ї, котрі пов'язані з вагітністю та пологами, а лише орієнтує психотерапевтів, психологів, членів сім'ї, у сорері сімейних відносин слід шукати причини дисгармонії [3, 7]. Сучасні дослідження мають розбіжності щодо переважання того чи іншого несприятливого типу ПКГД, що, звісно, залежить від контингенту вагітних, які брали участь у дослідженні, наявності ускладнень вагітності, способу розродження тощо.

МЕТА ДОСЛІДЖЕННЯ - на підставі оцінки психоемоційного стану вагітних провести аналіз характеристик гестаційної домінанти у контексті тривожності.

МАТЕРІАЛИ ТА МЕТОДИ. Обстежено 336 вагітних У II та III триместрах $((26,29 \pm 0,55)$ тижня). Середній вік жінок у групі дослідження склав $(27,48 \pm 0,46)$ року та знаходився в межах 17-40 років.

Індивідуально-психологічні особливості вагітних та їх психоемоційний стан досліджували з використанням комплексу психодіагностичних методів. Тестування проводилось як на паперових носіях, так і з використанням діагностичного комплексу «ReoCom» Stress у режимі «Класичний тест», який розроблений у лабораторії діагностичних систем Національного аерокосмічного університету «ХАИ-МЕДИКА» (м. Харків). Для встановлення типу ставлення до хвороби та інших, пов'язаних з нею особистісних відносин у вагітних 3 хронічними соматичними захворюваннями використовували Особистісний опитувальник Бехтерєвського інституту (ООБІ) [8]. Вагітні з дисгармонічним типом ставлення до соматичної хвороби в дослідження не включались. Для оцінки ситуативної (СТ) та особистісної тривожності (ОТ) використовувалась шкала Ч. Д. Спілбергера, яка адаптована Ю. Л. Ханіним [9]. 3 метою визначення типу переживання вагітності у майбутньої матері застосовано тест відносин вагітної I. В. Добрякова. Питання тесту відображають ставлення вагітної жінки до себе вагітної, до системи «мати - дитя», яка фрормується, до того, як до неї ставляться оточуючі, та визначають ПКГД [3, 4, 9]. Також проведена оцінка підтипів ПКГД [10]. 3 кожною вагітною було проведено бесіду про доцільність додаткових методів дослідження та отримана згода на їх проведення. Дослідження відповідає сучасним вимогам морально-етичних норм щодо правил ICH/GCP, Гельсінській декларації (1964), Конференції Ради Європи про права людини і біомедицини, а також положенням законодавчих актів України.

Обраний напрямок дослідження тісно пов'язаний 3 планом науково-дослідної роботи касредри акушерства і гінекології Запорізького державного медичного університету та є фррагментом докторської дисертації. 
Варіаційно-статистична обробка результатів здійснювалась 3 використанням ліцензованих стандартних пакетів прикладних програм багатовимірного статистичного аналізу «STATISTICA 6.0» (ліцензійний номер AXXR712D833214FAN5).

РЕЗУЛЬТАТИ ДОСЛІДЖЕНЬ ТА ЇХ ОБГОВОРЕННЯ. На сьогодні одним із надійних та інформативних способів оцінки рівня тривожності, з урахуванням ії рівня як стану - СТ, так і властивість особистості, що свідчить про стійку характеристику людини - ОТ. Середній показник рівня ОТ склав $(42,70 \pm 0,79)$ бала, а СТ - $(35,44 \pm 0,85)$ бала. Результати оцінки ОТ, які свідчать про тривожність як рису особистості, дозволили встановити, що у 330 (98,21\%) вагітних їі рівень виходить за межі низьких показників (рис. 1). Такі результати характерні і для СТ, але середні та високі показники були дещо нижчі та встановлені у 256 вагітних, що склало 76,19\%.

Серед жінок, які пройшли тестування, переважали особи з середнім рівнем ОТ (61,90\%). Як зазначалося раніше, у досить незначного відсотка вагітних (1,79\%) мав місце низький рівень ОТ, а високі показники ОТ встановлені у 36,31 \% вагітних. Оцінювання СТ дозволило встановити, що у 23,81 \% вагітних ії̈ рівень був низьким. Як і у випадку результатів дослідження ОТ, серед вагітних переважали особи з середнім рівнем СТ (63,99 \%). Високі значення при оцінці СТ встановлені у 12,20 \% вагітних.

Асрективно-мотиваційна трансформація жінки, яка перебуває у стані вагітності, розглядається у рамках дослідження гестаційної домінанти - системи вольових та інстинктивних патернів поведінки та світосприйняття. Аналізуючи бальну оцінку тесту відносин вагітної, середні показники якої представлені у таблиці 1, встановлено переважання відповідей, характерних для оптимального та ейсрорійного типів. Проте подальший аналіз дозволив встановити (рис. 2), що оптимальний варіант ПКГД встановлений лише у 41 (12,20\%) вагітної, а ейорорійний - у 3 (0,89 \%). У 292 вагітних, що склало 86,91\%, не встановлено переважання балів на користь конкретного типу ПКГД (тип, який відхиляється від оптимального).

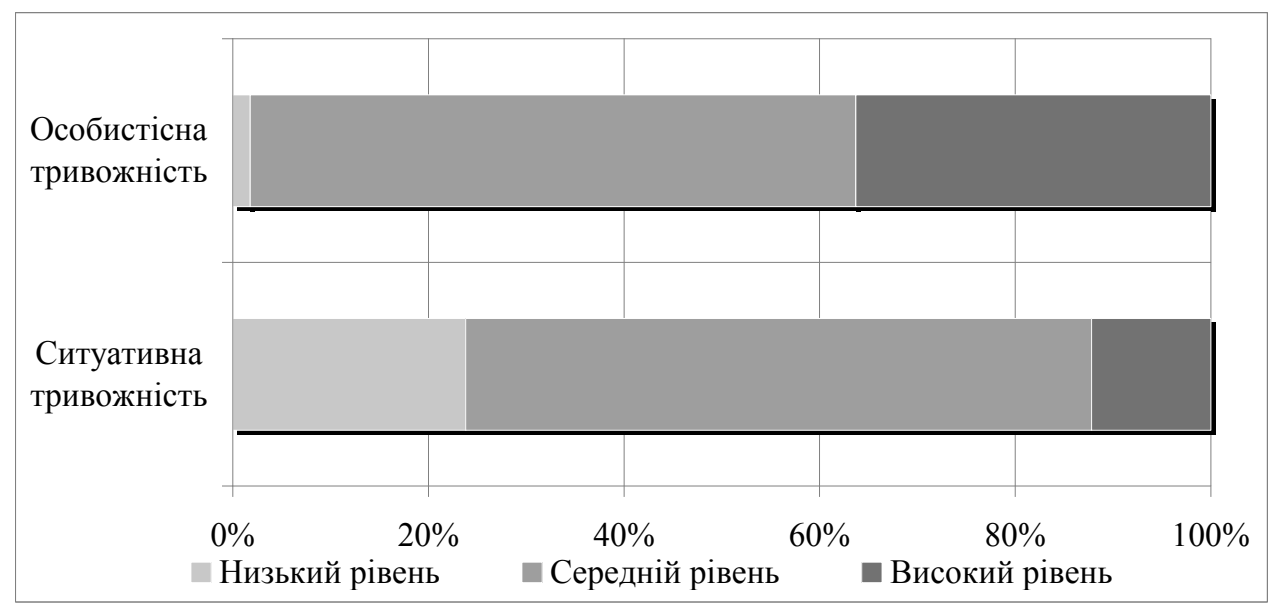

Рис. 1. Рівень тривожності у вагітних групи дослідження за результатами шкали Спілбергера - Ханіна (\%).

Таблиця 1. Середні показники за тестом відносин вагітної

\begin{tabular}{|l|c|}
\hline \multicolumn{1}{|c|}{ Показники бальної відповіді } & Бали \\
\hline Оптимальний тип & $4,67 \pm 0,18$ \\
\hline Гіпогестогнозичний тип & $0,85 \pm 0,12$ \\
\hline Ейорорійний тип & $2,76 \pm 0,18$ \\
\hline Тривожний тип & $0,63 \pm 0,09$ \\
\hline Депресивний тип & $0,07 \pm 0,03$ \\
\hline
\end{tabular}

Враховуючи такі результати, слід проаналізувати, які 3 обраних тверджень переважають та були найбільш значимі для жінки. Лідируючі позиції за оцінкою підтипів ПКГД мали оптимально-ейфорійний та ейфрорійно-оптимальний типи, які встановлені у 23,97 \% та 17,12 \% вагітних відповідно. Інші підтипи зустрічались 3 доволі низькою частотою. Так, оптимально-гіпогестогнозичний тип мав місце у 2,40 \% вагітних, оптимально-тривожний - у 2,06 \%, а ефрорійнотривожний - тільки у 1,03 \% вагітних. Слід зазначити, що зв'язку особливостей психоемоційного стану з терміном гестації та віком вагітних встановлено не було.

Аналіз характеристик гестаційної домінанти в контексті тривожності показав деяку залежність її показників. Серед-

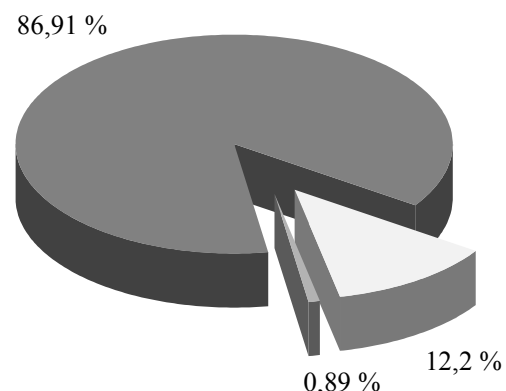

Оптимальний тип ПКГД

Ейфорійний тип ПКГД

П ПКГД, який відхиляється від оптимального

Рис. 2. Структура ПкГД серед вагітних груп дослідження (\%). 
ній показник балів, який характеризує оптимальний тип

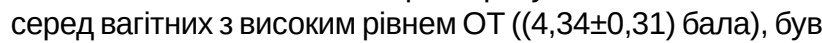
статистично достовірно $(p<0,05)$ нижчим, ніж відповідний показник серед вагітних з середнім ії рівнем $((4,88 \pm 0,22)$ бала). Слід зазначити, що серед вагітних з низьким рівнем ОТ відповідей, які характеризують тривожний та депресивний типи ПКГД, не було. Показник, який характеризує оптимальний тип та оцінений з урахуванням рівня СТ, був статистично достовірно $(p<0,05)$ нижчим у вагітних з високим рівнем СТ $((4,10 \pm 0,60)$ бала) порівняно з відповідним показником вагітних, як з середнім $((4,68 \pm 0,22)$ бала), так і низьким ії рівнем $((4,94 \pm 0,36)$ бала). Крім того, у вагітних 3 високим рівнем СТ встановлений статистично достовірно $(p<0,05)$ вищий рівень показника відповідей тривожного типу порівняно з вагітними з низьким їі рівнем $((0,93 \pm 0,35)$ та $(0,45 \pm 0,17)$ бала відповідно).

Такі результати свідчать про вплив тривожності на формування ПКГД, адже відомо, що будь-які негативні впливи середовища можуть негативно впливати на організм жінки, яка орормує материнську домінанту, що призводить до виникнення конкуруючої «стресової» субдомінанти $[3,11]$. Така домінанта буде значною мірою порушувати нормальний перебіг основної - гестаційної, що, в кінцевому результаті, не може не позначитися на фізичній та нервово-психічній сфрері майбутньої дитини, на ступені стійкості ії адаптаційних процесів до моменту народження [11].

\section{СПИСОК ЛІТЕРАТУРИ}

1. Функциональная межполушарная асимметрия. Хрестоматия / под ред. Н. Н. Боголепова, В. Ф. Фокина. - М. : Научный мир, 2004. - 728 с.

2. Добряков И. В. Как родить счастливого ребенка? / И. В. Добряков, М. М. Маляровская. - 3-е изд. - СПб. : Речь, 2008. $-160 \mathrm{c}$.

3. Добряков И. В. Перинатальная психология / И. В. Добряков. - СПб. : Питер, 2009. - 234 с.

4. Добряков И. В. Перинатальная психология / И. В. Добряков. - 2-е изд. - СПб. : Питер, 2015. - 352 с.

5. Щукина Е. Г. Сравнение особенностей психологического компонента гестационной доминанты у беременных и матерей / Е. Г. Щукина // Психология эффективного родительства : материалы Междунар. науч.-практ. конф. - Курск : КГМУ, 2011. - С. 586-592.

6. Добряков И. В. Семейные факторы, влияющие на формирование различных типов психологического компонента гестационной доминанты / И. В. Добряков // Российский психиатрический журнал. - 2011. - № 2. - С. 35-40.

7. Добряков В. И. Ретроспективное определение особенностей психологического компонента гестационной
Висновки. 1. Перебіг вагітності характеризується високим відсотком жінок із середньо-високими показниками як особистісної $(98,21 \%)$, так і ситуативної $(76,19 \%)$ тривожності, які не залежать від терміну вагітності та віку.

2. Оцінка психологічного компонента гестаційної домінанти дозволила встановити, що його оптимальний варіант мав місце лише у 12,20 \% вагітних, ейфорійний -у $0,89 \%$, а у більшості вагітних $(86,91 \%)$ не встановлено переважання балів на користь конкретного типу.

3. Аналіз характеристик гестаційної домінанти в контексті тривожності показав, що показник балів, який характеризує оптимальний тип та оцінений з урахуванням рівня СТ, був статистично достовірно $(p<0,05)$ нижчим у вагітних з високим рівнем СТ порівняно з відповідним показником вагітних, як з середнім, так і низьким їі рівнем.

4. Незважаючи на наявність того чи іншого типу або підтипу, які визначені по переважанню обраних тверджень, додаткове виділення проблемних підсистем у жінки, а також оцінка рівня тривожності у поєднанні 3 психологічним інтерв'ю дозволять зробити якісний аналіз та виявити ті відносини, які потребують корекції.

ПЕРСПЕКТИВИ ПОДАЛЬШИХ ДОСЛІДЖЕНЬ. Результати проведеного дослідження свідчать про доцільність оцінки впливу психоемоційного стану, а саме характеристик гестаційної домінанти у контексті тривожності, на частоту акушерських та перинатальних ускладнень.

доминанты / В. И. Добряков // Вопросы психического здоровья детей и подростков. - 2014. - № 2. - С. 71-75.

8. Менделевич В. Д. Клиническая и медицинская психология : учеб. пособ. / В. Д. Менделевич. - М. : МЕДпрессинсрорм, 2008. -432 с.

9. Астахов В. М. Психодиагностика в репродуктивной медицине / В. М. Астахов, О. В. Бацылева, И. В. Пузь. - Винница : ООО «Нилан-ЛТД», 2016. - 380 с.

10. Рабовалюк Л. Н. Выделение подтипов пКГд на основе теста отношений беременной И. В. Добрякова / л. Н. Рабовалюк // Социальные науки и общественное здоровье: теоретические подходы, эмпирические исследования, практические решения : материалы II Междунар. науч.-практ. конф., 20-21 апреля 2012 года. - Пенза Москва - Витебск : Научно-издательский центр «Социоcopepa», 2012.- C. 124-136.

11. Батуев А. С. Психосизиологические основы доминанты материнства / А. С. Батуев // Перинатальная психология и медицина. Сборник материалов конференции по перинатальной психологии (Санкт-Петербург, 3-5 октября 2003 г.). - СПб., 2003. - 145 с.

\section{REFERENCES}

1. Bogolepova, N.N., \& Fokina, V.F. (Eds.) (2004). Funktsionalnaya mezhpolusharnaya asimmetriya. Khrestomatiia [Functional interhemispheric asymmetry]. Moscow: Nauchnyi mir [in Russian].

2. Dobriakov, I.V. \& Maliarovskaya, M.M. (2008). Kak rodit shchastlivogo rebenka? [How to give birth to a happy child?]. St. Petersburg: Rech [in Russian].
3. Dobriakov, I.V. (2009). Perinatalnaya psikhologiya [Perinatal psychology]. St. Petersburg: Piter [in Russian].

4. Dobriakov, I.V. (2015). Perinatalnaya psikhologiya [Perinatal psychology]. St. Petersburg: Piter [in Russian].

5. Shchukina, E.G. (2011). Sravnenie osobennostey psikhologicheskogo komponenta gestatsyonnoy dominanty 
u beremennykh i materey [Comparison of the psychological component of the gestational dominant in pregnant women and mothers]. Psikhologiya effektivnogo roditelstva: Materialy mezhdunarodnoy nauchno-prakticheskoy konferentsii Materials of International Scientific and Practical Conference. Kursk: KGMU [in Russian].

6. Dobriakov, I.V. (2011). Semeinye faktory, vliyayushchie na formirovanie razlichnykh tipov psikhologicheskogo komponenta gestatsyonnoy dominanty [Family factors affecting the formation of various types of psychological component of the gestational dominant]. Rossiyskiy psikhiatricheskiy zhurnal - Russian Journal of Psychiaty, 2, 35-40 [in Russian].

7. Dobriakov, V.I. (2014). Retrospektivnoe opredelenie osobennostei psikhologicheskogo komponenta gestatsyonnoy dominanty [Retrospective identification of features of the psychological component of the gestational dominant]. Voprosy psikhicheskogo zdorovya detey i podrostkov - Mental Health of Children and Adolescent, 2, 71-75 [in Russian].

8. Mendelevich, V.D. (2008). Klinicheskaya i meditsinskaya psikhologiya [Clinical and medical psychology]. Moscow: MEDpress-inform [in Russian].
9. Astakhov, V.M., Batsyleva, O.V. \& Puz, I.V. (2016). Psikhodiagnostika $v$ reproduktivnoy meditsyne [Psychodiagnostics in reproductive medicine]. Vinnitsa: OOO «Nilan-LTD» [in Russian].

10. Rabovaliuk, L.N. (2012). Vydelenie podtipov PKGD na osnove testa otnosheniy beremennoy I.V. Dobriakova [Identification of PKHD subtypes on the basis of the pregnancy test I. V. Dobryakova] Sotsialnye nauki i obshchestvennoe zdorovie: teoreticheskie podkhody, empiricheskie issledovaniya, prakticheskie resheniya: materialy II mezhdunarodnoy nauchnoprakticheskoy konferentsii - Social sciences and public health: theoretical approaches, empirical studies, practical solutions: materials of the II International Scientific and Practical Conference. (pp.124-136). Penza - Moscow - Vitebsk: «Sotsiosfera» [in Russian].

11. Batuev A.S. (2003). Psikhofiziologicheskie osnovy dominanty materinstva [Psychophysiological foundations of the maternal dominant]. Perinatalnaya psikhologiya i meditsyna. Sbornik materialov konferentsii po perinatalnoy psikhologii - Perinatal Psychology and Medicine. Proceedings of the conference on perinatal psychology. (pp.145). St. Petersburg [in Russian]. 